Supplement of Atmos. Chem. Phys. Discuss., 15, 20743-20774, 2015

http://www.atmos-chem-phys-discuss.net/15/20743/2015/

doi:10.5194/acpd-15-20743-2015-supplement

(C) Author(s) 2015. CC Attribution 3.0 License.

(c) (i)

\title{
Toward enhanced capability for detecting and predicting dust events in the Western United States: the Arizona Case Study
}

\section{Huang et al.}

Correspondence to: M. Huang (mhuang10@gmu.edu)

The copyright of individual parts of the supplement might differ from the CC-BY 3.0 licence. 


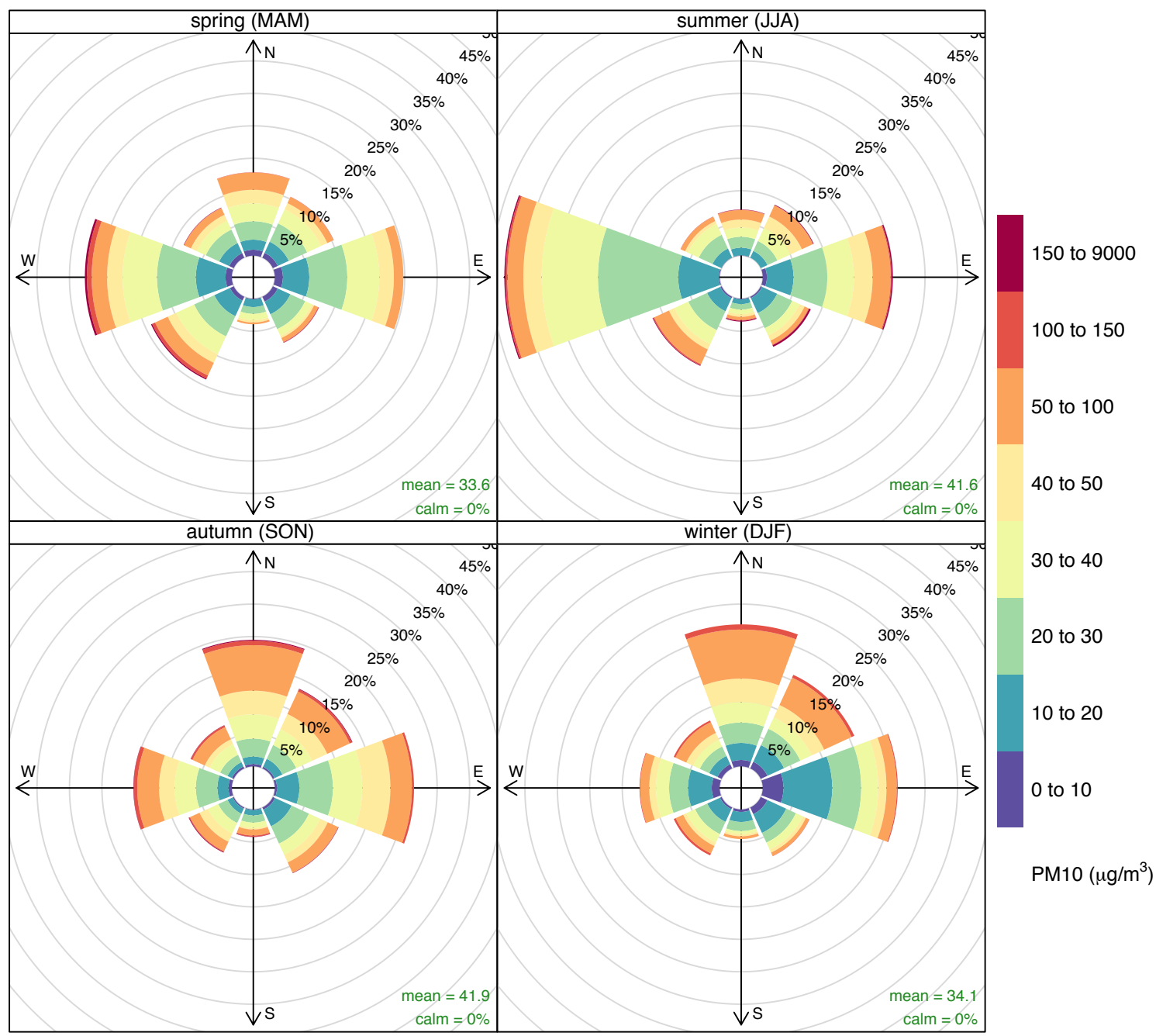

Figure S1. Frequencies of observed PM10 in Phoenix within various concentration intervals by wind directions in different seasons during Dec 2006-Nov 2007. 


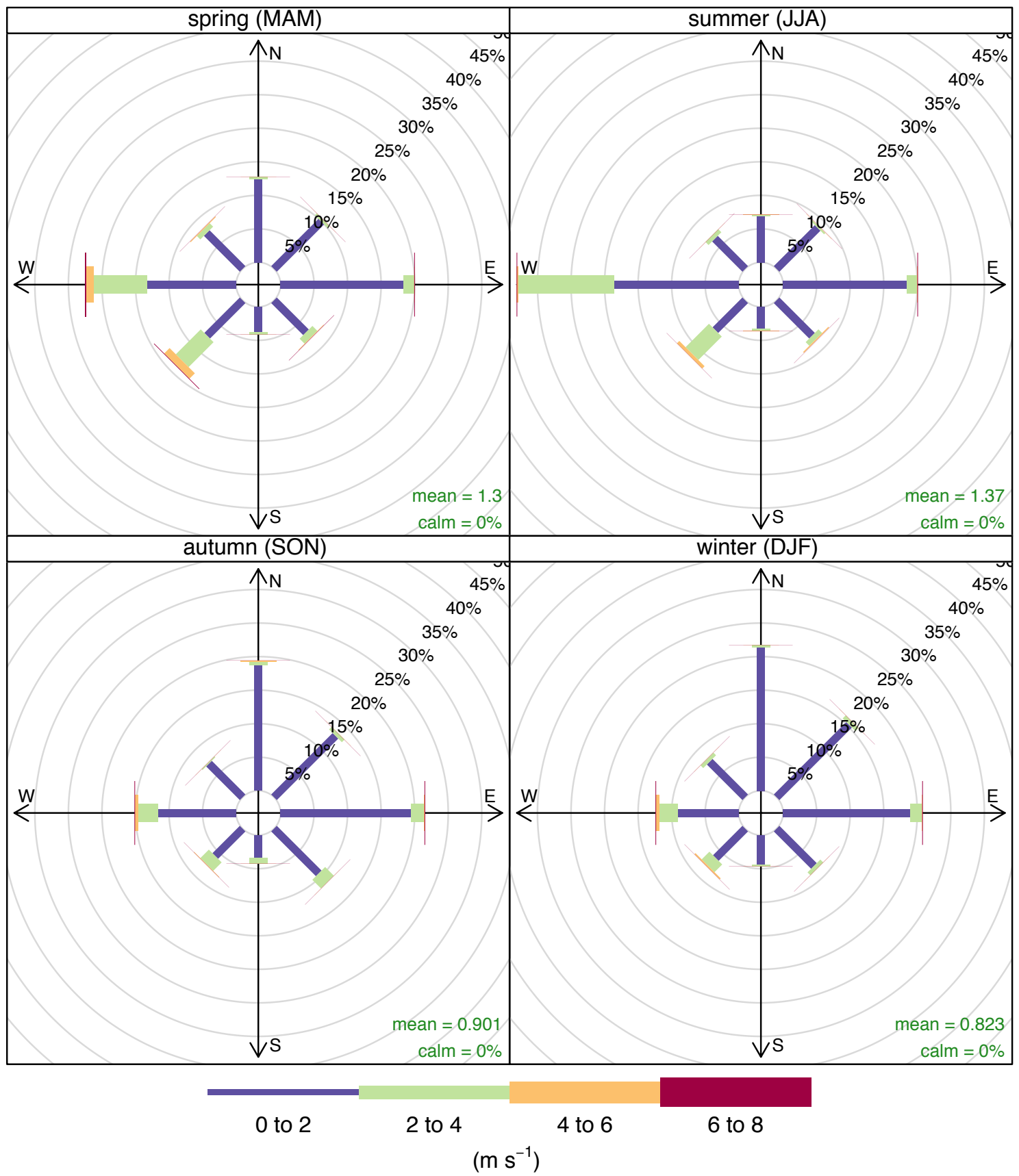

Figure S2. Phoenix observed wind roses in different seasons during Dec 2006-Nov 2007. 


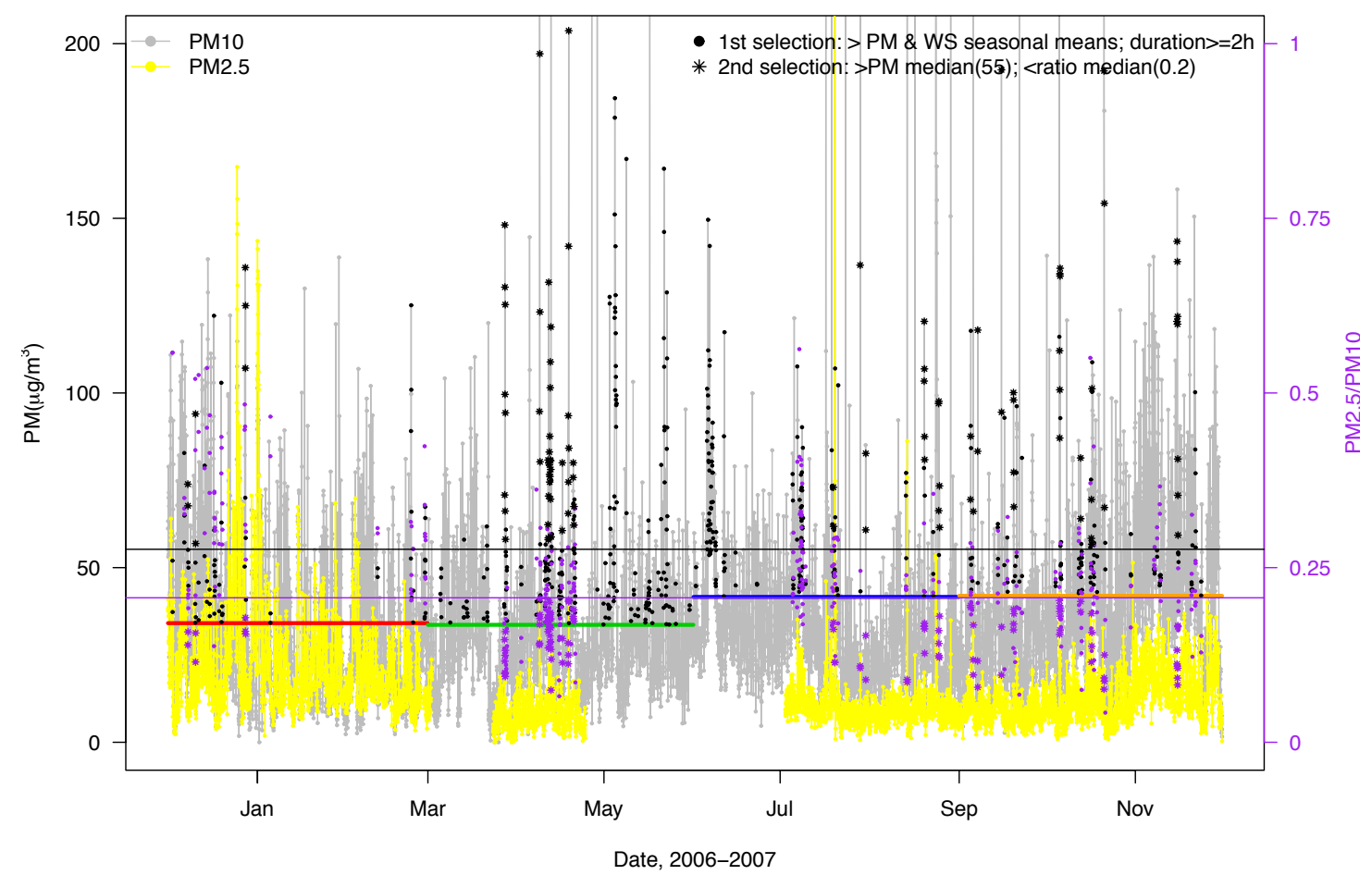

Figure S3. Time series of PM10 (grey), PM2.5 (yellow), and the PM2.5/PM10 ratio (purple) at Phoenix AQS site during Dec 2006-Nov 2007. Identified dust storm periods by two sets of criteria are highlighted in black dots and stars, respectively. Horizontal lines (red, green, blue and orange) indicate the seasonal mean PM10 concentrations at this site. Horizontal black and purple lines indicate the annual mean PM10 concentrations and PM2.5/PM10 ratios at this site.
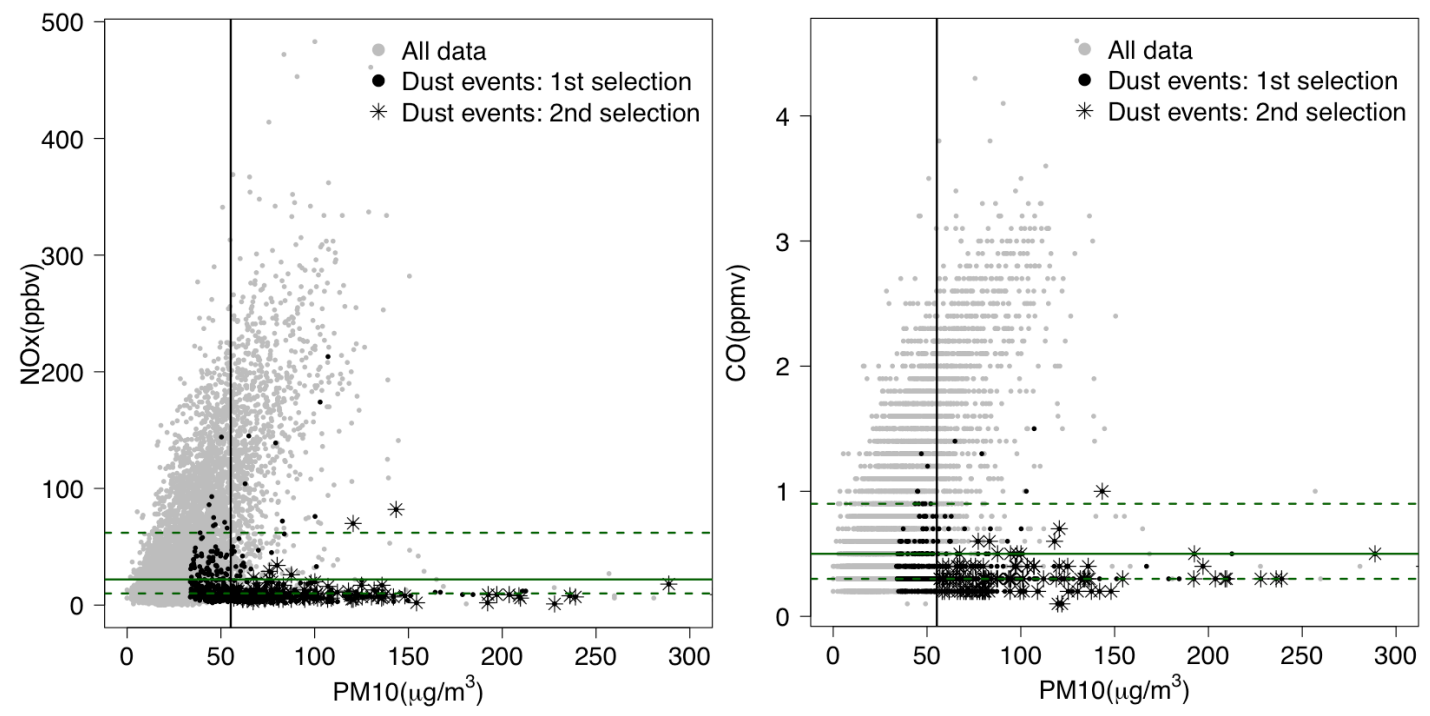

Figure S4. Validation of the identified dust events at the Phoenix AQS site during Dec 2006Nov 2007: Scatterplots of AQS hourly $\mathrm{NO}_{x}$ (left) and CO (right) versus PM10 concentrations. Identified dust periods by two sets of criteria are highlighted in black in black dots and stars, respectively. Green horizontal lines indicate the quartiles (median in solid lines, and $1^{\text {st }}, 3^{\text {rd }}$ quartiles in dashed lines) of $\mathrm{NO}_{\mathrm{x}}$ and $\mathrm{CO}$, and the vertical solid lines denote the median value of PM10. 